\title{
Validation \&Verification context for NPP design and construction
}

\author{
Gvozdev Vladislav ${ }^{1, *}$, and Kozinetc Galina ${ }^{1}$ \\ ${ }^{1}$ Peter the Great St. Petersburg Polytechnic University, Institute of Civil Engineering, 29 \\ Politechnicheskaya St., St. Petersburg, 195251, Russia
}

\begin{abstract}
Nuclear power, as one of the most sophisticated and technologically advanced industry sectors, sets very demanding safety requirements. Fulfilment thereof is mostly to be implemented and justified at the design and construction stages. The process of Validation and Verification $(\mathrm{V} \& \mathrm{~V})$ for such facilities should cover all possible disciplines and cases, therefore a systematic approach to its organization is needed, which is not fully. The article objective is to determine the reasons for such strict safety requirements and explore the methods for achieving it, including the $\mathrm{V} \& \mathrm{~V}$ process, as well as determining the factors $(\mathrm{V} \& \mathrm{~V}$ dimensions) forming the $\mathrm{V} \& \mathrm{~V}$ context, which is going to be used for choosing a specific type of $\mathrm{V} \& \mathrm{~V}$ activities (to be conducted during the design and construction phases). Then, the article shall determine the interrelations between disciplines that use the $\mathrm{V} \& \mathrm{~V}$ results depending on the context. $\mathrm{V} \& \mathrm{~V}$ Context is setting up the parameters defining specific $\mathrm{V} \& \mathrm{~V}$ activities. Generally, the V\&V Context includes the following dimensions: Discipline (Construction, Electrical, Instrumentation and Control), Hierarchy (Design Levels - Plant, System, Components and Structures levels), NPP Construction Project phases (Design, Construction, Installation, Commissioning). The $\mathrm{V} \& \mathrm{~V}$ process is a complex one and it will be different for each combination of the above-mentioned $\mathrm{V} \& \mathrm{~V}$ dimensions together forming the V\&V Context.
\end{abstract}

\section{Introduction}

The nuclear industry of Russia since the beginning of its existence remains a high-tech and competitive industry in the world market. Taking into account the specifics of the technological processes of power generation at NPPs (nuclear power plants), special attention is paid to the nuclear safety, and assuring the safety in any conditions is the key task for the whole industry. [1]

At the same time, the history of NPP development [1-3], and the analysis of nuclear accidents and disasters raises issue of confirming compliance with the safety requirements as the most important one. Manly those requirements, are implemented in the Design and performed during the NPP construction and compliance with the safety requirements as well as appropriate fulfilment of Design functions shall be guaranteed as much as it

\footnotetext{
* Corresponding author: vladislav.p.gvozdev@ gmail.com
} 
possible. The main tool for such guarantees of safety requirements fulfilment and ensuring the nuclear safety is validation and verification process $(\mathrm{V} \& \mathrm{~V})$ as presented in [4].

The reasons of Hight importance of Nuclear safety was investigated in scientific literature, publications and articles such as $3[3,5-7]$ etc. by different countries. The issue of Nuclear Safety and approach to achievement thereof was investigated and reviewed in international publications. 3 As the example, for the NPP the general methods for Safety achievement is presented in [1], specific requirements are presented in [4]. And as described in the above-mentioned publication the main part for ensuring of safety - its Design and Construction. Where all Design solutions to be verified, and safety functions guaranteed to be met.

The V\&V process specifically for construction was not deeply investigated for the complicated Civil structures such as NPP. Generally, the NPP industry requirements to the $\mathrm{V} \& \mathrm{~V}$ are presented in the IAEA (International Atomic Energy Agency) Safety standards (such as $[7,8]$ ) as part of the management system.

Moreover, investigation of $\mathrm{V} \& \mathrm{~V}$ process for the specific disciplines was not investigated sufficiently and systematically. This process was reviewed in very specific, precise cases (kind of V\&V dimensions) like software [9, 10], I\&C (Instrumentation and Control) [11], Nuclear testing [12], etc, but it was not conducted in the systematic way as the for the whole NPP as the complex industrial object. V\&V measures for each of NPP disciplines such as I\&C, Electrical, Process, etc. (as the structures of NPP Design) will be various, based on phase of $\mathrm{V} \& \mathrm{~V}$ implementation, design level and discipline for which $\mathrm{V} \& \mathrm{~V}$ is applied. Those parameters ( $\& \& \mathrm{~V}$ context) have not been analyzed and reflected systematically in the scientific publications yet.

The correlation between various disciplines (such Quality Control, System Qualification and Licensing), which use the results of $V \& V$ activities (sometime similar results) from point of view of Qualification Context was not investigated in the publications as well.

Thus, the V\&V process specifically for NPP Construction process, its context and dimensions as well as related disciplines were not investigated in details. Based on this research the objectives of this work are as follows:

1. To define reasons of strict requirements for NPP safety and methods of safety establishment, including V\&V process.

2. To define and formulate $\mathrm{V} \& \mathrm{~V}$ context based on the factors affecting the $\mathrm{V} \& \mathrm{~V}$ processes as an aggregate of $\mathrm{V} \& \mathrm{~V}$ dimensions that directly influences the scope and types of specific $\mathrm{V} \& \mathrm{~V}$ measures to be performed in one or another case.

3. To define disciplines that utilize V\&V results at various design and construction phases.

\section{Methods}

In the course of the V\&V survey used at the NPP Design and Construction phases the following method was applied:

- The reasons for stricter requirements were analyzed through the study of the Nuclear Power Industry development history in Russia and abroad.

- Various methods of the NPP safety assurance, including the V\&V process of design solutions applied in the course of the construction of the NPP as a complex facility, were analyzed.

- The factors (V\&V Dimensions) affecting the types of applied V\&V measures for confirmation of fulfilment of requirements and safety functions set by the NPP design were determined.

- Based on V\&V Dimensions the V\&V Context was formed as a total of those factors, influencing the $V \& V$ process. 
- Interconnections (with regard to V\&V Context) between various disciplines (Quality Control, Qualification, Licensing) utilizing the V\&V results were established.

\section{Results and discussion}

\subsection{Nuclear Safety}

As the world's history of nuclear energy development has shown, among obvious benefits such as low fuel consumption and independence from oil and gas, environmental friendliness (in case of compliance with technological processes of energy production), nuclear power is also a serious threat, for in case of violation of standard processes, the integrity of nuclear power plant structures can be compromised with high pressure and temperatures being a result of a nuclear reaction, which is accompanied by a prompt and essential temperature increase and the risk of radioactivity release beyond the plant safety barriers that can result in emergencies and accidents, which, depending on their severeness, can lead to serious human losses and environmental disasters [3, 4, 13].

Nowadays, a modern NPP appears to be one of the most complex industrial civil facilities with the strictest requirements being set thereto. The cause analyses for such level of requirements demands the current state of the nuclear industry and NPPs development history (including nuclear disasters that happened in the past) to be analysed $[2,3,13,16]$.

Accidents can be caused by both operator's error (human factor) and equipment and system failure (industrial factor). The severest NPP-related accidents were: Chernobyl NPP accident in 1986 [1, 2, 13-15], Three-Mile Island NPP accident in the USA in 1979 [1], and Fukushima-1 NPP in Japan in 2011 that resulted in human losses, serious environmental contamination and enormous expenses related to the liquidation of the accident aftermath. $[5,15]$.

Protection is achieved through the use of numerous engineered safety features at NPPs, where in addition to systems that ensure the implementation of standard technological processes for the electricity production (normal operation functions), nuclear power plants are equipped with sophisticated security systems that already perform safety functions with multi-level protection, safety barriers and redundancy, which excludes the possibility (ensures a minimum probability) of the release of radioactivity beyond the plant.

Design parameters are being determined for every engineered safety features and then deterministic analysis confirms whether such safety feature is capable to resist accidents it is intended for or not. Also, the safety of the project is assessed by probabilistic methods, which will confirm that the application of measures to prevent, control and mitigate the consequences of accidents (performance of safety functions) is thus structured so that the total risk is very small, and that none of the ways of development of the accident, no matter how low or high its probability is, would not make a disproportionately big contribution to the risk in comparison with other possible ways of the accident development. Safety functions and the requirements for systems, components and elements (including civil structures) that ensure implementation thereof are being presented both by NPP designers, who lay the basic engineering solutions allowing to ensure safety, and by the state authorities, that regulate nuclear, radiation and technical safety of nuclear power plants. [4, 18-21].

International organizations, such as the International Atomic Energy Agency (IAEA), monitor the non-proliferation of nuclear weapons and set the requirements on the basis of the analysis of accidents that have already occurred, the experience gained in operating nuclear power plants and the best practices of the member countries. 
Requirements can be applied directly for the equipment, systems, components and civil structures that perform safety functions, and also to the processes of the NPP construction and operation (design, manufacturing, installation, commissioning, etc.), for their management systems, competence, quality, etc.

Verification and validation of all these requirements must be ensured at all stages of the NPP life cycle at all its levels and must guarantee the safety of the NPP under any conditions which makes it one of the highest priorities of modern nuclear energy $[4,7,8]$.

\subsection{Validation \& Verification context and dimensions}

NPP (nuclear power plant) design is based on the defence-in-depth approach. According to this approach, a high level of the plant safety shall be attained by means of reliable safety functions (e.g. Reactor heat removal, Control of reactivity, prevention of reactivity expansion) and multiple redundant structural barriers that limit the release of radioactive substances into the environment. [3, 4].

This design is based on the requirement stetted up by the legislation and other binding documents, regulatory body and international nuclear standards requirements, the requirements of the contract for NPP construction (requirements for specific NPP), relevant government and regulatory body requirements (different kind of laws, acts, decrees, regulatory documents), Designer experience (can be incorporated in the contract). Part of design shall follow the Conventional standards requirements.

Ensuring of the Safety functions and requirements fulfilment shall be demonstrated and justified by the V\&V process for the whole life-cycle of NPP (starts from Design to Decommissioning).

Since the scope of NPP construction, is huge and the physical nature of items is versatile and measures to demonstrate the fulfilment of safety requirements vary from phase to phase, following dimensions can be determined to structures for the V\&V activities to bring them into more manageable areas: Nature, Hierarchy and Phase.

Depending on the determined dimensions $V \& V$ measures are selected in order to fulfill the safety requirements and ensure fulfilment of the safety functions in each applicable combination of those dimensions

Nature (or discipline) where the $\mathrm{V} \& \mathrm{~V}$ actions belong to. In this part following main disciplines were selected:

- Mechanical (Process) - contains the Process systems and all mechanical equipment such as Valves, Pumps, Pressure Vessels, Tanks, Draining Components, Heat Exchangers and Filters, Piping, Piping Fittings and Penetrations, HVAC (heating, ventilation, air conditioning) Components, etc.;

- Electrical - contains the system of power distribution, power supply, external power transmission, lighting, earthing (grounding), and the electrical equipment which are the parts of those systems: electrical cabinets, electrical cables, batteries, battery chargers, generators, busducts, busbars, circuit breakers, rectifiers, switchgears, transformers, inverters, etc. This discipline is applicable for the electrical parts of mechanical equipment, such as motors and actuators;

- Instrumentation and Control (I\&C) - the discipline contains, simulators, automated systems and related equipment including hardware (panels, controllers) and software and also field devices including transmitters, instruments, impulse lines;

- Civil - contains civil structures and parts of buildings (such as Reactor building, Safety building etc.) and structures (such as Ventilation stack etc.) of the NPP.

Hierarchy. Three main levels of NPP construction can be introduced: Plant, System and the Equipment levels. Additionally, the Architecture level shall be implemented in the I\&C discipline. 
- Plant level - its purpose is to establish top criteria for the NPP safety (Plant level safety requirements). This level consists of the concept approach for each discipline, presents the Defense-in-depth (DiD) principles and safety boundaries. Plant level includes the Initiating Events for all anticipated operational occurrences and accidents occurring in plant power operation mode and endangering the integrity of the nuclear fuel in the reactor, it contains the NPP task categories - functional entities which further will be broken down into functions as is.

- Architecture level - Tasks categories will be broken down into safety functions on the architectural level and then systems, which will perform those functions will be assigned at this level.

- System (building) level - presents the systems, belonging to one or another discipline, fulfilling safety functions. Buildings, where those systems are located belongs to this level as well.

- Equipment (component) level - consists of equipment and structures as parts of system, perform their function in frame of system.

Phase. The V\&V actions will vary from phase to phase upon fulfilment of the requirements and safety functions to be confirmed by the different V\&V measures. The following main Phases can be indicated:

Design, including the Basic and Detailed Design, Manufacturing and Construction, Installation, Commissioning, Operation and maintenance, Decommissioning.

\section{V\&V in Licensing, Qualification, Quality control.}

The V\&V actions performed within the abovementioned dimensions and context are applied to different processes:

Licensing $\mathrm{V} \& \mathrm{~V}$ activities are the upper level measures, and these evidences (collected from all other levels and processes) shall be provided to the regulatory body to justify the NPP Safe Design (as part of Licence application). It refers to the activities related to plant, architecture, and system level qualification process for achieving explicit license (which is the final evidence of safety requirements fulfilment) i.e. Construction and Operating License. Licensing also covers the activities for providing the evidence that the involved organizations are capable of performing their responsibilities and acting according to the requirements. Licensing documents are used to achieve appropriate license (Construction and Operating license) and provide information for different stakeholders about the documentation to be submitted in different phases of the Project.

Qualification as the process of obtaining evidences (qualification records) of the capability of the qualification items to perform the functionality or purpose as intended (functional qualification) in a specified physical environment (seismic and environmental qualification). Qualification is about collecting evidences of Safety functions and requirements fulfilment at the System and Equipment (component) levels and providing them for Licensing. Qualification is focusing on the integrity and reliable function of architectures, systems, platforms and individual components and leading to their approval in scope of whole NPP and include any applicable and necessary qualification activities (functions qualification, electrical qualification, environmental qualification, etc.) and V\&V actions within them. Qualification documents are technical matter (especially at the lower levels) providing information on the actual design and analysis/testing processes to be used to confirm fulfilment of functions and safety requirements.

Quality process gives the means to ensure that safety, quality and environment protection requirements at work are taken into account and fulfilled. The quality control evidences could be used for the qualification. 


\section{Conclusions}

Thus, following the foregoing objectives and methods, during the research the following results have been achieved:

1. Currently, the nuclear industry is one of the leaders in the energy sector. However, among numerous advantages, the NPP has a number of limitations, first of all related to the risk of radioactivity release which leads to nuclear incidents and accidents.

2. To prevent the recurrence of nuclear incidents and accidents, such as Chernobyl or Fukushima, ensuring safety of modern NPP Projects is the top priority for the nuclear industry. First and foremost, safety is achieved by a complex of process systems and the safety buildings and structures that are part of the NPP design (Construction), which must prevent or mitigate any possible equipment failures or operators' mistakes and, under any conditions, under any environmental influences by fulfilment of the safety functions.

3. To ensure the Safety functions performance and safety requirements fulfilment, the project management approach and the manageable Validation and Verification process (V\&V process) to be used.

4. $V \& V$ process is a complex and $V \& V$ actions will vary for different disciplines, design levels and project phases. To handle them in manageable conditions V\&V context shall be determined. V\&V Context is setting up the parameters defining specific V\&V activities. Generally, the V\&V Context includes the following dimensions: Discipline (Construction, Electrical, Instrumentation and Control), Hierarchy (Design Levels - Plant, System, Components and Structures levels), NPP Construction Project phases (Design, Construction, Installation, Commissioning).

5. The results of V\&V activities may be handled by the various processes depending on the Context: Quality process mostly through the Quality control at the equipment (component level), by qualification as Qualification evidences at the System level and by the Licensing at the Plant level.

\section{References}

1. R.E. Hester, R.M. Harrison, Nuclear Power and the Environment, (2011)

2. V.A. Sidorenko The history of nuclear energy of the USSR and Russia, (2002)

3. V.A. Sidorenko, Energiia: ekonomika, tekhnika, ekologiia, (2012)

4. INSAG-12 Basic safety principles for nuclear power plants: 75-INSAG-3 rev. 1 / a report by the International Nuclear Safety Advisory Group. — Vienna: International Atomic Energy Agency, 1999.

5. I. Hotynchan, I. Tkachenko Analysis of ensuring safety at nuclear power plants, (2015)

6. M. El Baradei. Ensuring nuclear safety \& security (2001)

7. IAEA Safety standards series No. GSR Part 2, Leadership and management for safety (2016)

8. IAEA Safety standards series No GS-G-3.1, Application of the management system for facilities and activities (2006)

9. A.V. Egorov, S.N. Filimonov, V.V. Artisyuk, A.N. Shmelev, Verification of SCALE 5 (2008) 
10. L. Abramov, A. Bakhmetyev, I. Bylov, A. Vasyuchenkov, Development and verification of a software system for probabilistic safety analysis of nuclear installations project direction, pRoRYV (2016)

11. IAEA Technical reports series \# 384 Verification and Validation of Software Related to Nuclear Power Plant Instrumentation and Control (1999)

12. J.F. Evernden, Verification of nuclear testing (1985)

13. E.V. Ametistova, Fundamentals of the modern power industry (2008),

14. L.A. Bolshova, N. P. Laverova, Linge Problems of the nuclear legacy and the ways of their solution, 3 (2015)

15. A.V. Yablokov, V.B. Nesterenko, V.A. Nesterenko, Chernobyl: Consequences of the Catastrophe for People and the Environment (2007)

16. Official web-site of ROSATOM State Atomic Energy Corporation URL: http://www.rosatom.ru/

17. M.S. Baxter, Commercial nuclear power, assuring safety for the future journal of environmental radioactivity (1999)

18. NE-BP Nuclear energy basic principles. Vienna: International Atomic Energy Agency (2008).

19. NP-T-2.7 Project management in nuclear power plant construction: guidelines and experience, Vienna: International Atomic Energy Agency, (2012).

20. G.E. Zhuravlyov, Psychological Foundations of Safety Culture in Nuclear Energy and Industry, (1996)

21. J. Harvey, G.Erdos, H.Bolam, D.Gregory, An examination of different safety cultures in a nuclear processing plant (2002) 